\title{
DÜBLIN
}

Technological University Dublin ARROW@TU Dublin

\section{Evaluating HRD Programmes}

Sue Mulhall

Technological University Dublin, Sue.Mulhall@TUDublin.ie

Follow this and additional works at: https://arrow.tudublin.ie/buschmanbk

Part of the Business Administration, Management, and Operations Commons

\section{Recommended Citation}

Mulhall, S. (forthcoming 2015) 'Evaluating HRD Programmes', in Carbery, R. and Cross, C. (eds.) Human Resource Development: A Concise Introduction, Hampshire, Palgrave Macmillan.

This Book Chapter is brought to you for free and open access by the School of Management at ARROW@TU Dublin. It has been accepted for inclusion in Books/Book Chapters by an authorized administrator of ARROW@TU Dublin. For more information, please contact arrow.admin@tudublin.ie, aisling.coyne@tudublin.ie, gerard.connolly@tudublin.ie.

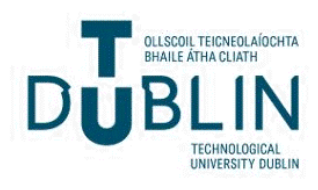




\section{Chapter 10}

\section{Evaluating HRD Programmes}

\section{Sue Mulhall}

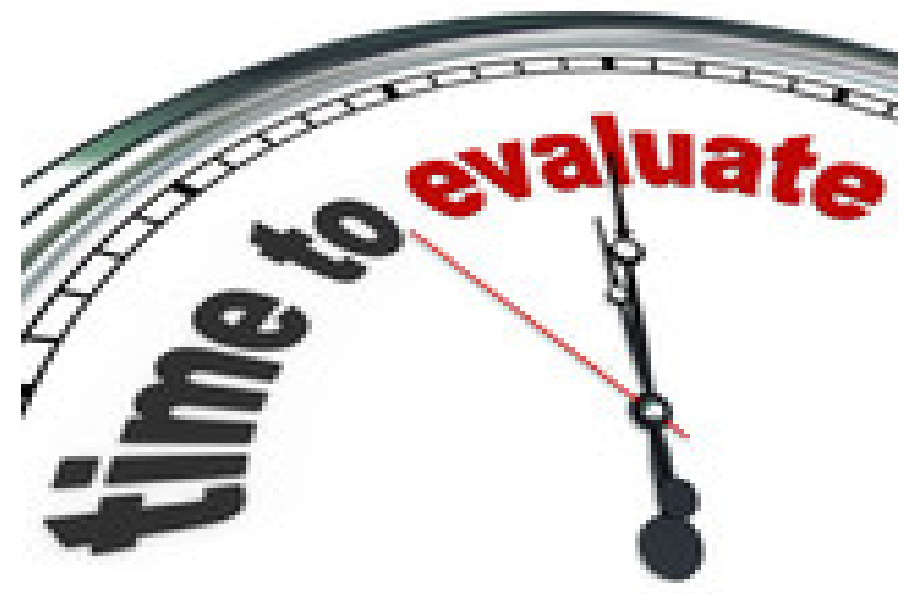

http://en.fotolia.com/search?cca $=1000000 \& \mathrm{k}=$ evaluating+training\&filters $\% 5$ Bcontent type $\% 3 A$ all $\% 5 \mathrm{D}=1 \&$ submit.x=23\&submit.y=12

Caption: Take time out to evaluate

\section{[A] Learning Outcomes}

By the end of this chapter you should be able to:

- Explain the concept and purpose of HRD evaluation

- Know why it is important to evaluate

- Discuss the different philosophical approaches to evaluation and the associated models

- Explain when evaluation should take place

- Identify what can be evaluated in HRD

- Describe how evaluation can take place

- Outline how learning transfer can occur in the workplace

\section{[A] Introduction}


In this chapter we look at the concept of evaluation. Without realising it, we evaluate events all of the time. Before a potentially difficult encounter we may consider what to say and do, and anticipate the possible reactions of the other person. During the interaction we try to remember our pre-planned objectives so as not to become too involved in the actuality of the occurrence. After the experience we reflect on what happened, what was said and by who, how it was stated, and why the incident unfolded as it did. We also deliberate on whether we achieved what we set out to accomplish and consider the implications for our future dealings with the individual. Evaluating HRD programmes in a company is similar to how we gauge the interpersonal relationships in our own lives. We focus on the " $5 \mathrm{~W}$ 's and $1 \mathrm{H}$ " (who, what, when, where, why and how), that is, questions whose answers are deemed essential in preparing for, participating in, and then assessing the outcome of a situation. Despite this apparently logical approach to evaluation many organisations do not evaluate their HRD activities. They put forward a host of reasons for not evaluating, including that it is overly time consuming, excessively costly and unnecessary as everyone has to have some training for their job. Given the time and money involved in HRD, however, providing evidence of the value of this activity to the organisation is important from a return on investment perspective. This chapter commences with the "where" of evaluation by locating it within an organisational setting, and then relating the "what" and the "why" by explaining the concept and the basis for its use. We then discuss "when" evaluation should occur and "who" may be concerned with the information emanating from the process. We place a strong emphasis on the "how" of evaluation by detailing the main models available and their associated measures. The chapter ends with a discussion of how to create a culture of effective evaluation.

\section{[A] Explaining the Concept of Evaluation (Where, What and Why)}

We begin by explaining what evaluation is and outline the background to evaluation, thereby linking it in with strategic HRD [MAKING LINKS: See Chapter 2]. We also explore the purpose of evaluation by summarising the rationale underpinning the process of assessing HRD interventions.

\section{Figure 10.1 Process of HRD Cycle}




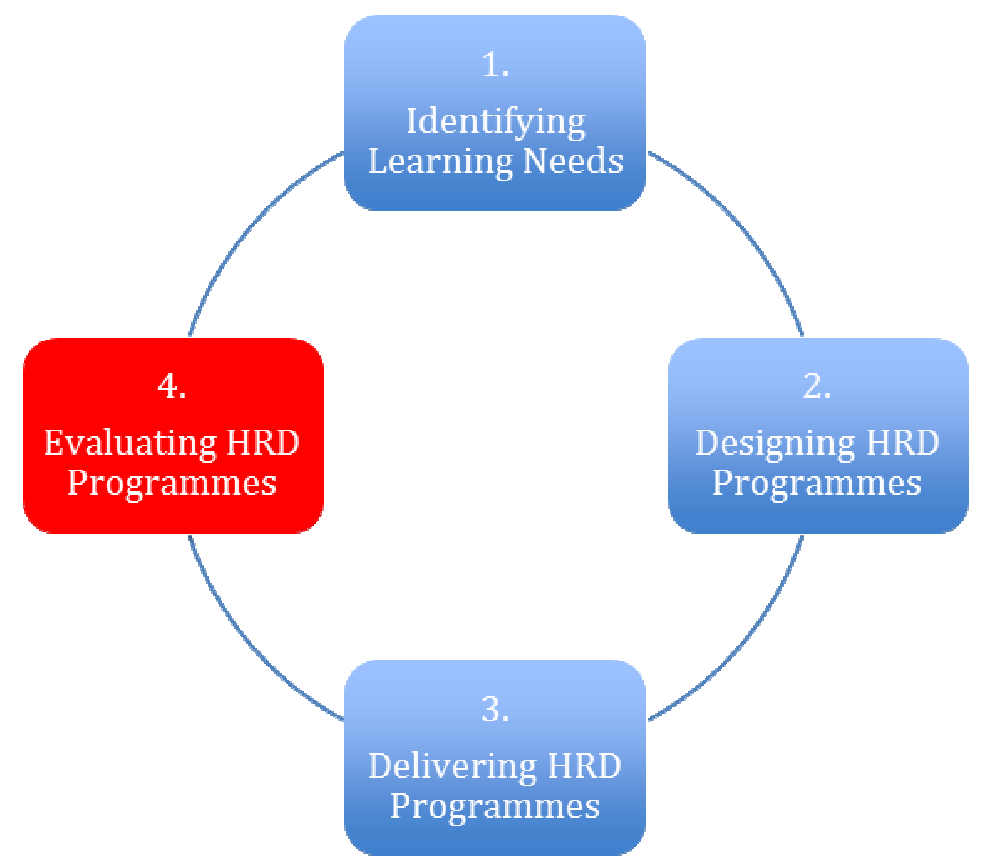

In the previous three chapters, we discussed how to identify HRD needs and then design and deliver a programme to satisfy those requirements [MAKING LINKS: See Chapters 7, 8 and 9]. There should be a strong and clear relationship between these three phases and the final stage in the process of HRD cycle (see Figure 10.1), evaluation [KEY TERM: systematic determination of a subject's merit, worth and significance, using criteria governed by a set of standards, which assist in the identification of changes to future programmes]. Evaluation influences the design and the delivery of HRD interventions because the output from an evaluation exercise becomes the input to any future training needs analyses (TNA). It should, therefore, be an integral feature of the HRD cycle, occurring before, during and after each learning event, highlighting the continuous, on-going nature of the evaluation process.

This chapter interprets the term evaluation in its broadest sense by using Hamblin's (1974) definition, describing evaluation as "any attempt to obtain information (feedback) on the effects of a training programme and to assess the value of the training in the light of that information" (p.8). Evaluation involves the measurement and use of data concerning the outcome, that is, the effectiveness, of a HRD intervention (Armstrong, 2014; Blanchard and Thacker, 2013; McGuire and Mølbjerg Jørgensen, 2011). Good management practice indicates that all organisational 
activities are routinely examined to ensure that they occur as planned and produce the anticipated results. Without such a review, corrective action cannot be taken to address situations that do not transpire as intended, and, thus, generate the expected effects. Similar to all other functional areas, the HRD department is obliged to engage in an audit of its practice to demonstrate that it is contributing to organisational effectiveness through aligning its activities with the business strategy (Swart et al., 2005). The term effectiveness is a relative concept, typically determined with respect to the achievement of a goal or a set of goals (Werner and DeSimone, 2012). HRD effectiveness must be viewed in relation to the goals of the learning programme(s) being assessed. It entails the comparison of objectives with outcomes to identify whether the intervention has achieved its purpose (Armstrong, 2014). The formulation of objectives and the establishment of methods to measure the ensuing results are an essential element of the design phase of a learning programme (first stage in the systematic HRD cycle). The evaluation phase of the HRD cycle (fourth and final stage) provides guidance on what is required to ascertain whether these learning events are effective.

\section{[Beginning of boxed feature: Spotlight on Skills]}

As the HRD Director of a multinational mobile phone company, you are responsible for the learning needs of 5,000 staff in the Europe, Middle East and Africa (EMEA) region of the business. Your department coordinates the needs assessment, design, delivery and evaluation of learning programmes for all organisational grades, from production operative to Chief Executive, and for all functional areas, including manufacturing, logistics and supply chain, sales and marketing, retail, finance and HR. At a recent Board meeting you presented an evaluation review noting that the return on investment $(\mathrm{ROI})$ for learning activities during the current financial year was 10 per cent lower than the previous period, despite the same expenditure level. The Board has asked you to prepare a report recommending initiatives to ensure that the learning ROI improves for the forthcoming year, without either decreasing the budget (€1.5m per annum) or the annual allowance per employee (€300). Consider the following issues:

- Where will you access the information to inform your decisions?

- Who will you liaise with? 
- What will you recommend to the Board?

- How will you rationalise your proposals?

\section{[End of boxed feature]}

\section{[B] Purpose of evaluation}

Learning activities are not ends in themselves. Organisations need to establish if these activities are successful, what worked well and was the cost justified by the outcome of the activity. This means that we should evaluate to discover whether the learning activities add value and enhance employee capability (Martin et al., 2010). Evaluation, can, therefore, be (Easterby-Smith, 1986) summative [KEY TERM: assessing the effectiveness of the outcomes against those specified when the activity was planned; usually takes place at the end of an intervention], formative [KEY TERM: focuses on continual improvement, indicating where improvements or changes are necessary to make the programme more effective], or oriented to learning [KEY TERM: assessing the extent to which the person can transfer the content of the programme to the job and improve performance].

All three forms of evaluation (summative, formative, or learning assessment) entail gathering information and generating knowledge to facilitate decision-making within companies (Blanchard and Thacker, 2013; Bramley, 2003; McGuire and Mølbjerg Jørgensen, 2011; Phillips and Gully, 2014; Werner and DeSimone, 2012). The evaluation of HRD programmes is, consequently, situated within the wider organisational context (Harrison, 2009; Swart et al., 2005). It attempts to understand the process of cause and effect by analysing how learning can impact on individual behaviour, group and departmental targets, and, ultimately, corporate efficiency and effectiveness. For example, Simmonds (2003) argues that evaluation can provide firms with answers to the following questions:

- How effective was the TNA?

- How useful were the learning strategies and methods that were used?

- What was the reaction of the learners and facilitators to the activities?

- To what extent have those who participated in the intervention acquired the intended knowledge, skills and attitudes (KSA)? 
- What changes in workplace performance and behaviour are attributable to the learning programme?

- To what degree have the learning events contributed to the attainment of organisational goals?

HRD evaluation involves, therefore, the systemic collection of information necessary to make effective learning decisions related to the selection, adoption, value, and modification of various instructional activities (Werner and DeSimone, 2012). This type of data allows managers to make informed decisions about various aspects of the HRD process, including (Bramley, 2003; Martin et al., 2010; Phillips, 2011; Phillips and Gully, 2014; Werner and DeSimone, 2012):

- Determining whether a programme is accomplishing its objectives.

- Identifying the strengths and weaknesses of the initiative, which can lead to adjustments as required.

- Ascertaining which participants benefited the most, or the least, from an activity.

- Discovering which participants are transferring what they learned to their job.

- Deciding who should participate in future programmes.

- Collating data to promote future programmes.

- Establishing the cost-benefit ratio of a programme.

- Justifying resource allocation.

- Building the credibility of the HRD process with key internal and external customers.

\section{[Beginning of boxed feature: Consider This ....]}

Take the example of a fictitious international car components company. The firm manufactures its products in China and ships them to a large warehouse situated at its European Headquarters in Dublin. From this central location, the organisation distributes the car parts throughout Europe. During a recent stock audit, a marked increase in the number of breakages was detected, particularly glass-based products, such as windscreens, mirrors, headlamps, indicator casings, and bulbs. The root cause was identified as human error, mainly due to inappropriate practices by the fork-lift drivers when stacking the merchandise. The firm scheduled a training 
course on the correct loading/unloading procedures for all of the warehouse fork-lift drivers. How will the training course cause a change in the number of breakages? What information will the company need to determine the effectiveness of this programme?

\section{[End of boxed feature]}

\section{[A] Establishing the Output of Evaluation (When and Who)}

In this section we explore the information (output) generated through the evaluation process that assists corporate decision-making, with particular reference to when the evaluation should occur and who may be interested in the resultant data.

\section{[B] Information - type and timing}

The two types of information (output) from the evaluation phase of the systematic HRD cycle that aid organisational decision-making are referred to as process and outcome data (Blanchard and Thacker, 2013). Evaluation designed to provide feedback so that improvement of the programme can take place is called process evaluation [KEY TERM: compares the designed and developed intervention to what actually takes place in the real-life experience]. It coincides with evaluation conducted before and during a learning event. In contrast, evaluation constructed as a terminal activity to represent success or failure, akin to a report card, is termed outcome evaluation [KEY TERM: finds out about the effect of the learning on the participant, the job, and the organisation by investigating how well the HRD activity has achieved its objectives]. This occurs when an assessment is carried out upon completion of a learning initiative and on return to the workplace.

In relation to the first type of data, process evaluation, the actual intervention is assessed against the expected (as planned) programme to provide an appraisal of the effectiveness of the learning implementation (Swart et al., 2005). This facilitates

a review of the learning process and the intended outcomes. The analysis is divided into two timeframes - before and during the learning (Blanchard and Thacker, 2013). The "before" element involves investigating the steps used to develop the activity, that is, prior to delivery. For example, exploring:

- Were learning needs diagnosed correctly? 
- Were needs correctly translated into learning objectives?

- Was an evaluation system devised to measure the accomplishment of the learning objectives?

- Was the programme formulated to meet all of the learning objectives?

- Were the methods employed suitable for each of the learning objectives?

The "during" component entails determining whether all of the systems planned into the programme were actually carried out. For example, examining:

- Were the facilitator, learning techniques, and learning objectives well matched?

- Were the teaching portions of the learning effective?

- Did the facilitator utilise the various learning methodologies appropriately (e.g. case studies, role-plays, individual exercises, and group activities)?

- Did the facilitator adhere to the learning design and lesson plans?

With regard to the second type of data, outcome evaluation, various end result information yardsticks are studied to establish the degree to which the learning met or is meeting its goals (Blanchard and Thacker, 2013). The four outcome evaluation results that are probably the best known are reaction, learning, behaviour, and organisational data (Kirkpatrick, 1959), which are explored in greater detail in the Section on "Models of Evaluation" later in this chapter:

- Reaction outcomes influence how much can be learned and provide information on the participant's perceptions, emotions, and subjective interpretations of the learning experience.

- Learning outcomes affect how much behaviour can alter on return to the job and supply information on how well the learning objectives were achieved.

- Behaviour outcomes are the changes of performance and behaviour on-thejob that will influence company results and present information on the degree to which the learned behaviour has transferred to the job.

- Organisational outcomes are the variations in corporate metrics [KEY TERM: measures of a firm's activities and operational functioning] related to the rationale for the learning intervention in the first place. They provide information on the organisational performance gaps identified in the TNA so 
that any divergence can be utilised as the baseline for calculating an improvement in results following the completion of the learning programme.

\section{[B] People - interest and importance}

To determine what evaluation data (process or outcome) should be used when assessing the effectiveness of a learning event, we ask the question, "who is interested in the information collected?" In response, the HRD department is primarily concerned with process information to analyse how they are doing. The customers of training (defined as anyone with a vested interest in the HRD department's activities, such as learners and their supervisors), however, usually pay more attention to outcome evaluation than to process evaluation (Blanchard and Thacker, 2013). The output of evaluation (process and outcome data), can, therefore, be viewed as important from three different perspectives: gauging the success of learning initiatives; assessing the design effectiveness of the associated activities; and judging the return on investment (ROI) [KEY TERM: involves a comparison of the costs and pay-offs of the learning event] from these interventions. The key participants in the HRD process will attach varying levels of importance to these three positions (Swart et al., 2005). In the first case (gauging success), the persons attuned to this form of evaluation will most likely be the learners who took part in the actual process (and possibly their supervisors and colleagues). They will place an emphasis on identifying the degree of success at obtaining the learning objectives. The second position (effectiveness of design) would generally be aligned with the standpoint of the designers and facilitators of the intervention, plus the HRD department. Their focus will centre on taking action to improve the planning and delivery of the programme and to consider the results of the learning, rather than concentrating simply on activities (Garavan et al., 2003). Moving onto the third evaluation position (ROI), those drawn to this would probably be the people who made the learning possible, that is, the decision-makers at organisational level who secured the budgetary resources (Swart et al., 2005).

\section{[Beginning of boxed feature: Consider This ....]}

Returning to the learning requirements of the previously mentioned car components company, when devising the evaluation process for the fork-lift driver lifting procedures course, the firm has to take into account the information needs of the 
various participants. It has to ascertain the appropriateness, or otherwise, of the learning objectives, pedagogical methods and facilitator approach utilised during the learning activity. Additionally, it has to determine the fork-lift drivers' opinion of the course and what additional knowledge and skills they acquired and applied in their jobs after undergoing the training. Identifying the number of car component breakages, particularly with regard to glass-based products, would also be beneficial. Would you have the same issues to consider if the fork-lift drivers worked in a warehouse in a large electrical and white-goods retailer?

\section{[End of boxed feature]}

\section{[A] Exploring the Models of Evaluation (How)}

How should a company manage the process of evaluating a HRD programme? There is no consensus response to this question, with Anderson (2007) maintaining that a prescriptive panacea to evaluation is unsuitable because firms should introduce bespoke solutions aligned to their specific requirements. It has been suggested that there are two different philosophical approaches to conducting HRD evaluations (Pilbeam and Corbridge, 2010). Hierarchical models, focusing on levels of outcomes within an organisation, can be distinguished from contextual models, incorporating a broader situational perspective to evaluation. By examining a company's HRD strategic plan, it is possible to identify what learning interventions should be assessed, at what levels, how they should be reviewed, and what evaluation models are applicable (Blanchard and Thacker, 2013) [MAKING LINKS: See Chapter 2].

\section{[B] Hierarchical models}

Hierarchical approaches are sometimes referred to as scientific/quantitative models, and rely on techniques that focus on objective measurement so that the costs and benefits of any learning activity can be measured, thereby calculating a ROI (Pilbeam and Corbridge, 2010). Such frameworks assess the economic benefits of learning (Phillips, 2011), which may include generating cost savings (e.g. decreasing unit costs), creating time savings (e.g. achieving enhanced order response rates), facilitating productive work habits (e.g. reducing absenteeism), developing the skills base of learners (e.g. resulting in fewer product defects), and improving the workplace climate (e.g. engendering greater job satisfaction). 
The most popular approaches within hierarchical evaluation models are ones that emphasise levels of measurement, which delineate the contributions that learning can make for the different constituents in an organisation (Pilbeam and Corbridge, 2010). Such frameworks require that data be quantifiable and based on predetermined aims (Gunnigle et al., 2011) and the evaluation process is constructed to meet those objectives (Bramley, 2003). These approaches envisage that if each level is evaluated, it is possible to have a more complete understanding of the full effects of HRD interventions. For example, if participants enjoy the programme (level 1), they are likely to learn (level 2). If participants learn, they are predisposed to change their on-the-job performance and behaviour (level 3). If participants alter their work performance and behaviour, the learning is liable to have a business impact (levels 4 and 5). Every level necessitates a different evaluation strategy and is seen as a measure of the progressive transfer and application of learning content. As Table 10.1 indicates, numerous hierarchical models incorporating levels of measurement have been proposed. The most widely used hierarchical approach is the Kirkpatrick model, with the majority of frameworks incorporating his four levels of evaluation to a greater or lesser extent, either as explicit steps in the process, or as information collected within these steps. Examples of companies using these models are found across the globe. A large retail chain in Latvia utilises the Kirkpatrick model (Enkuzena and Kliedere, 2011), a major garment exporter draws upon the Phillips model to evaluate their management training initiatives (De Alwis and Rajaratne, 2011), and an executive coaching programme in South Africa was assessed with Brinkerhoff's model (Beets and Goodman, 2012).

Difficulties have been identified with this category of models (Blanchard and Thacker, 2013; Werner and DeSimone, 2012). For example, research suggests that there is a poor relationship between positive reaction-level assessments, learning, changes in job performance/behaviour, and the application of learning to the workplace (Devins and Smith, 2013). Studies have identified some linkages (for example, Alliger et al., 1997; Colquitt et al., 2000; Liebermann and Hoffmann, 2008) demonstrating that reactions affect learning outcomes, and learning outcomes influence transfer to the job. Few investigations, however, have attempted to link 
these transmission effects to organisational metrics due to the difficulty of factoring out other variables, particularly external elements, related to these outcomes (Blanchard and Thacker, 2013). 
Table 10.1 Summary of Key Hierarchical Evaluation Models

\begin{tabular}{|c|c|c|}
\hline Model & Description & Comments \\
\hline \multirow[t]{3}{*}{$\begin{array}{l}\text { Kirkpatrick's (1959, } \\
\text { 1979, 2007) } \\
\text { Four-Level Model }\end{array}$} & $\begin{array}{l}\text { Proposes evaluation along a hierarchy } \\
\text { of learning outcomes: } \\
\text { Level } 1 \text { (reactions) - the response of } \\
\text { learners to the content and methods of } \\
\text { the intervention are elicited. }\end{array}$ & $\begin{array}{l}\text { This measures the satisfaction of the participants with the } \\
\text { learning context, programme structure, content and methods, } \\
\text { facilitator style, and assessment type. It constitutes a formative } \\
\text { evaluation. }\end{array}$ \\
\hline & $\begin{array}{l}\text { Level } 2 \text { (learning) - the actual learning } \\
\text { of participants achieved during a } \\
\text { programme is measured and an } \\
\text { assessment is made regarding how well } \\
\text { they have advanced in their level of } \\
\text { knowledge and skills. }\end{array}$ & $\begin{array}{l}\text { participants arising from the intervention. The overall degree of } \\
\text { learning can be shaped by a number of factors, such as } \\
\text { participant motivation, prior learning experiences, learning } \\
\text { design, learning delivery, and perceived relevance of the } \\
\text { material. It constitutes a formative evaluation. }\end{array}$ \\
\hline & $\begin{array}{l}\text { Level } 3 \text { (behaviour, also known as } \\
\text { transfer of learning) - the effect of the } \\
\text { event on the performance and } \\
\text { behaviour of the learner on his/her }\end{array}$ & $\begin{array}{l}\text { The transfer level assesses how well learning is employed in } \\
\text { the workplace. The scale of transfer may be increased by } \\
\text { improving the connection between the learning context and the } \\
\text { performance context, in addition to enhancing workplace }\end{array}$ \\
\hline
\end{tabular}




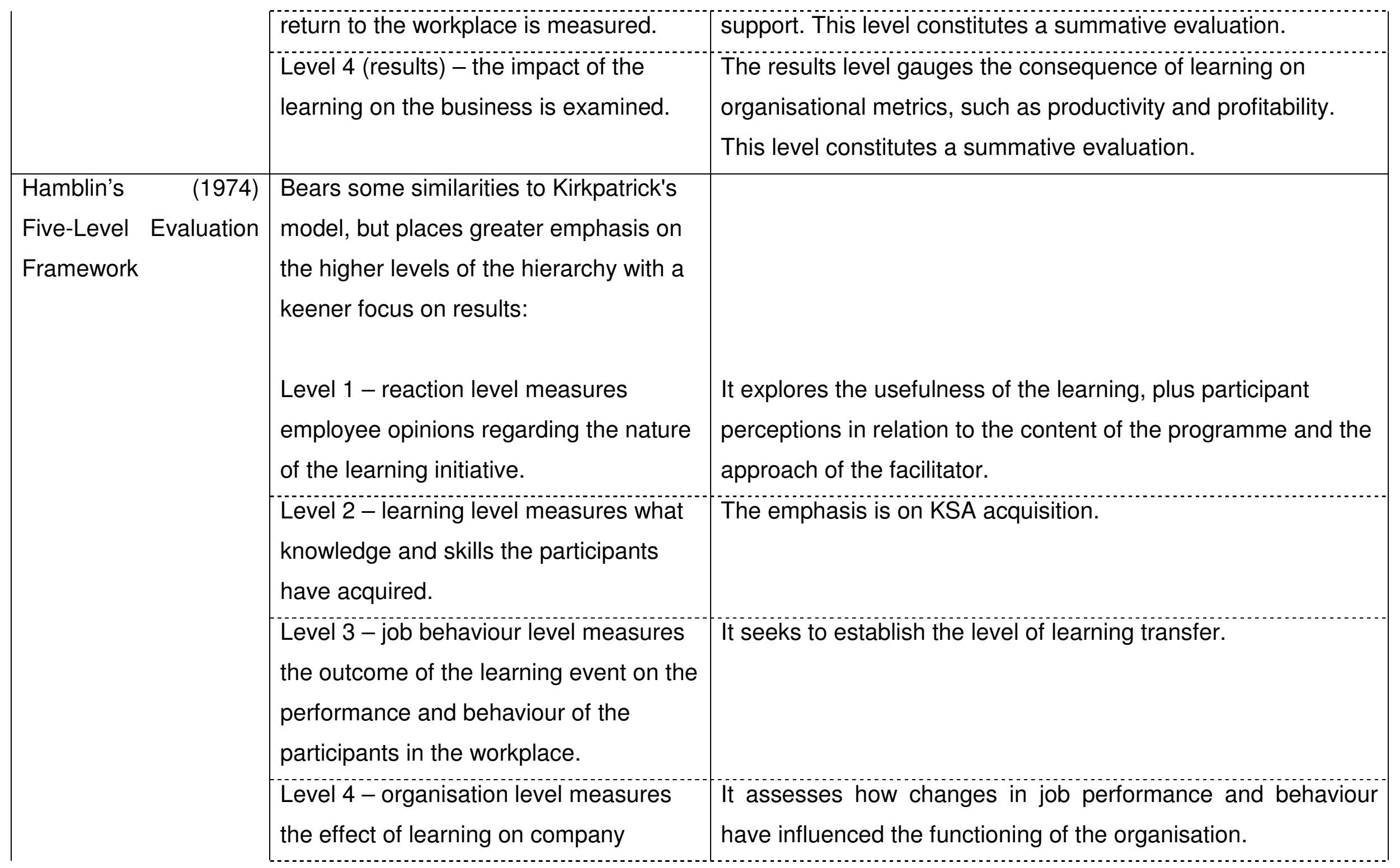




\begin{tabular}{|c|c|c|}
\hline & \multicolumn{2}{|l|}{ metrics. } \\
\hline & $\begin{array}{l}\text { Level } 5 \text { - ultimate value measures how } \\
\text { the company has benefited as a totality } \\
\text { from the learning intervention. }\end{array}$ & $\begin{array}{l}\text { This is analysed in terms of organisational ratios, such as } \\
\text { growth, profitability, and productivity. }\end{array}$ \\
\hline $\begin{array}{l}\text { Phillips' (1991, 1997, } \\
\text { 2011) ROI Model }\end{array}$ & $\begin{array}{l}\text { Incorporates a fifth level of return on } \\
\text { investment (ROI) to Kirkpatrick's four- } \\
\text { level model by measuring the monetary } \\
\text { value of the results and costs of a } \\
\text { learning programme. The five levels are } \\
\text { called reaction and planned action, } \\
\text { learning, applied learning on-the-job, } \\
\text { business results, and ROI. }\end{array}$ & $\begin{array}{l}\text { Establishing the ROI of learning justifies current and future } \\
\text { budget spends, facilitates the tracking of costs, increases the } \\
\text { prediction of revenue based on improved service and product } \\
\text { selection, and enhances the organisation's understanding of } \\
\text { corporate measures (e.g. number of accidents, turnover, and } \\
\text { absenteeism). }\end{array}$ \\
\hline $\begin{array}{l}\text { Brinkerhoff's (1987) } \\
\text { Six-Stage Model }\end{array}$ & $\begin{array}{l}\text { Explores how a learning programme can } \\
\text { be modified to become more successful, } \\
\text { thus it differs in focus to the previous } \\
\text { three frameworks by suggesting a cycle } \\
\text { of six overlapping steps, appreciating } \\
\text { that difficulties identified in a particular } \\
\text { phase are possibly caused by } \\
\text { occurrences in a previous stage. }\end{array}$ & $\begin{array}{l}\text { The earlier stages of the systematic HRD cycle (needs } \\
\text { assessment, design, and delivery) are explicitly incorporated } \\
\text { into this approach, thereby assisting HRD professionals to } \\
\text { recognise that evaluation is an ongoing activity, not just an } \\
\text { endeavour that is carried out post-implementation. }\end{array}$ \\
\hline
\end{tabular}




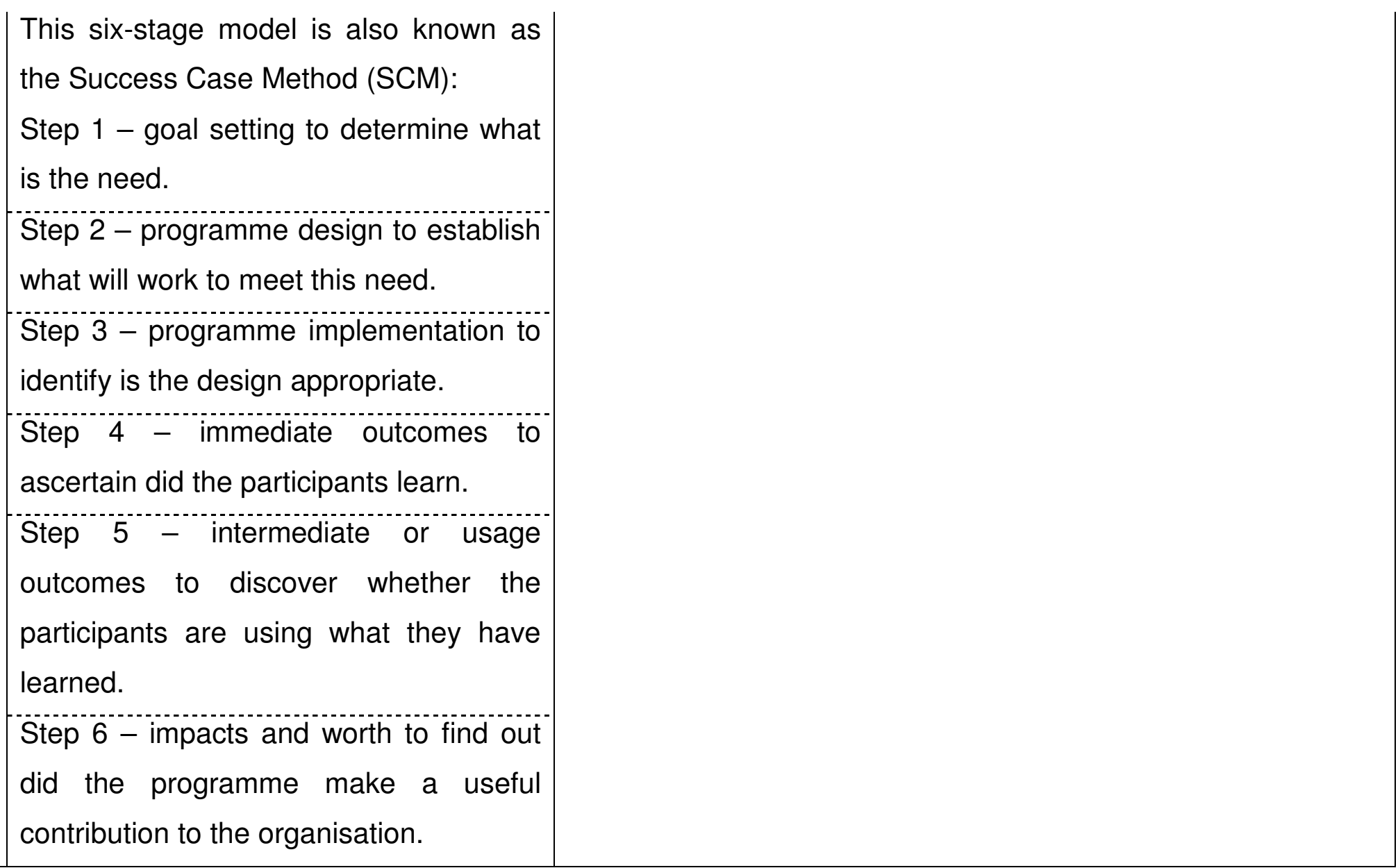

Based on ideas presented by Garavan et al. (2003), Marchington and Wilkinson (2012), Martin et al. (2010), McGuire and Mølbjerg Jørgensen (2011), and Werner and DeSimone (2012). 


\section{[B] Contextual models}

The limited scope of hierarchical models has led to the development of another cluster of frameworks - contextual perspectives - that adopt a more expansive approach to evaluation. They emphasise the enhancement of learning processes, in contrast to simply focusing on substantiating the worth of learning programmes. Contextual models, therefore, include tangible and intangible benefits, such as learner expectation, and corporate culture and values, so that the long-term consequences of learning can be assessed.

Models that adopt a contextual philosophical approach take into account the situation in which a company operates. Systems theory refers to the way in which organised collectives respond in an adaptive manner to cope with transformation in their external environments to ensure that their basic structures remain intact. It offers HRD practitioners a contextual evaluation framework. For example, such models have been used by Korean companies when evaluating web-based and classroom-based management training programmes (Kong and Jacobs, 2011). The CIRO model, developed by Warr et al. (1970), explores four aspects of learning evaluation - context, inputs, reactions, and outputs:

- Context analyses factors such as the identification of needs and objectivesetting in relation to the company's culture, thereby positioning the programme within a broader setting. It involves deciding whether a particular issue has a learning solution, rather than, for example, relating to a resource constraint.

- Input examines the design and delivery of the activity and how individual interventions are framed. It can occur during the actual event, or following the completion of the initiative.

- Reaction explores the process of collating and reviewing the feedback received with regard to the learning experience. The participants' responses to the learning event are central to this element.

- Output gauges outcomes along three dimensions (immediate postintervention modifications, learning transfer to the workplace, and impact on departmental and organisational performance). It assesses the extent to which the planned objectives were achieved. 
A systems-oriented framework to evaluation is also advocated by Easterby-Smith (1986, 1994), who suggests considering the following issues:

- Context assesses the features surrounding the learning intervention, such as organisational culture, values, the provision of appropriate support, and the availability of technology.

- Administration considers how the event is promoted and communicated to potential participants. It reviews pre-programme instructions, location of the course, and expectations conveyed to learners.

- Input investigates the various components of the initiative, such as learning techniques to be used, topics to be covered, and layout of the classroom.

- Process studies the content of the programme and the mechanisms by which the syllabus is delivered. It focuses on how learning is structured and the experiences of the participants.

- Output examines the developments that occur as a result of the HRD activity. At the individual level, this centres on KSA change, and at the organisational level, it explores corporate metrics.

Anderson (2007) maintains that the traditional hierarchical models of evaluation concentrate on the reactions and consequences for learners and facilitators resulting from discrete and individual interventions. She argues for a strategic perspective stressing the aggregate value contribution made by a more diverse range of learning processes and stakeholders. This stance has been termed a responsive approach to evaluation, that is, it considers how the intervention is perceived by various concerned parties (Bramley, 2003). Designed in conjunction with the Chartered Institute of Personnel and Development (CIPD), the Partnership Model of Learning (Anderson, 2007) highlights the interconnections and responsibilities of the learner, the learner's supervisor, senior management, and the HRD department. The model is concerned with ensuring that learning and organisational strategies are aligned and it views the purpose of evaluation as establishing this strategic integration. Internal factors (learning and ROI) and external elements (benchmarking and capacity indicators, that is, corporate metrics) are included into the evaluation process. This framework also recognises the subjective nature of evaluation by considering return on expectations [KEY TERM: the extent to which stakeholder 
expectations have been met by the HRD programme, while simultaneously assessing the associated potential monetary value of those expectations]. The Partnership Model of Learning concentres on four main areas of evaluation:

- Learning function emphasises the efficiency and effectiveness of the HRD department. It assesses how the learning intervention is provided and the competence of the personnel within the function.

- Return on expectations (ROE) explores the anticipated benefits of the programme and whether these have been achieved. It identifies what progress, if any, has occurred as a result of the programme.

- Return on investment (ROI) examines the benefits arising from the initiative relative to the costs incurred over a specific timeframe. It analyses how learning is contributing to the attainment of key performance targets.

- Benchmark and capacity indicators compare the learning activity to a set of internal and external standards. It enables a company to gauge its performance against established in-house and industry norms, thus promoting a climate of continuous improvement.

\section{[A] Examining Measures of Evaluation (How)}

Regardless of the model employed for evaluation the difficulty for most organisations lies in identifying a set of tools that can facilitate the effective evaluation of learning interventions. The methods used must accurately and fairly measure what they are intended to measure (be valid), in addition to exhibiting preciseness in measurement over time (be reliable).

It is possible for a company to draw upon two different types of measurement approaches:

- Quantitative methodologies: investigations of phenomenon that can be counted and enumerated using statistical, mathematical or computational techniques provide an account of the "what" of the learning (e.g. the number of people involved, and the size of the learning investment). This form of evaluation data is gathered by calculating outcomes and by scoring behaviours on pre-determined scales (Swart et al., 2005). 
- Qualitative methodologies: exploration of phenomenon based on individual interpretation and meaning using interviewing and observational techniques offer a sense of how a programme functions and the implications that this may generate for all of the parties involved. It is related to how people "feel" and how they have "experienced" the process. This form of evaluation data is accessed by asking people questions that allow them to express their opinions, or by monitoring their behaviour (Swart et al., 2005).

Quantitative and qualitative information can be collected through the deployment of a varied array of measurement instruments. These devices can be employed with both hierarchical and contextual models of evaluation.

\section{[B] Measures for hierarchical models}

The measurement tools that can be drawn upon to gauge outcomes at the various levels of the Kirkpatrick, Hamblin, Phillips and Brinkerhoff frameworks are outlined in Table 10.2. The decision relating to what method to adopt should be made during the early stages of the systematic HRD cycle because many of the mechanisms require a baseline of current performance against which to assess the impact of the intervention (a "before and after" comparison). The measurement approach to be used, therefore, should be selected prior to the commencement of a learning intervention, ideally at the design phase of the cycle.

\section{[C] Level 1}

Instruments at the first level of an evaluation hierarchy (reactions) measure whether learners perceive that a particular initiative was of benefit to them as individuals. Such devices seek to investigate the view of the participants regarding the value and relevance of the learning, their enjoyment of the endeavour, the competence levels of the facilitators, and their satisfaction ratings of the content, structure, and delivery of the activity. Opinions may also be garnered about the facilities, including location, transport arrangements, room size and layout, technological supports, and catering services. Gathering information about the participant's reactions to the learning event is usually achieved by using a quantitative technique like a questionnaire (Garavan et al., 2003; Marchington and Wilkinson, 2012; Swart et al., 2005), however, other 
qualitative mediums, such as interviews and group discussions, are equally legitimate.

Table 10.2 Summary of Hierarchical Measures of Evaluation

\begin{tabular}{|l|l|}
\hline Level & Measures \\
\hline Level 1 (reactions) & $\begin{array}{l}\text { Questionnaires, feedback sheets (sometimes called } \\
\text { happy sheets, smile sheets or reactionnaires), oral } \\
\text { discussions, surveys, interviews, and checklists. }\end{array}$ \\
\hline Level 2 (learning) & $\begin{array}{l}\text { Before and after tests, examinations, portfolios, } \\
\text { projects, learning logs, and simulations. }\end{array}$ \\
\hline Level 3 (behaviour) & $\begin{array}{l}\text { Interviews, observation, critical incident techniques, } \\
\text { pre- and post-programme testing, reflective journals, } \\
\text { performance appraisals, and attitude surveys. }\end{array}$ \\
\hline Level 4 (results) & $\begin{array}{l}\text { General workplace metrics (e.g. profits and turnover) } \\
\text { and specific workplace indicators (e.g. levels of } \\
\text { absenteeism and accidents). }\end{array}$ \\
\hline Level 5 (ROI) & \begin{tabular}{l} 
Cost-benefit analysis techniques. \\
\hline
\end{tabular}
\end{tabular}

Based on ideas presented by Garavan et al. (2003), Gunnigle et al. (2011), Marchington and Wilkinson (2012), Martin et al. (2010), McGuire and Mølbjerg Jørgensen (2011), and Phillips and Gully (2014).

There are two types of reactions level questionnaires available at stage one of an evaluation hierarchy - affective and utility (Blanchard and Thacker, 2013). An affective questionnaire assesses feelings about the learning programme (e.g. "I found this training enjoyable"), whereas a utility questionnaire appraises beliefs about the relevance of the intervention (e.g. "This training was beneficial for me"). The following steps have been suggested when compiling either an affective or utility reactions level questionnaire (Blanchard and Thacker, 2013):

- Determine what issues need to be measured.

- Develop a written set of questions to obtain the information.

- Construct a scale to quantify the participant's answers.

- Make the survey anonymous so that learners feel free to respond honestly. 
- Ask for details that might be useful in ascertaining differences in reactions by subgroup, such as age, gender, occupation, and grade.

- Provide space for additional comments to allow learners the opportunity to mention topics that the questionnaire designer may not have considered.

- Decide the most appropriate time to distribute the survey to collect the information required:

- If the questionnaire is handed out immediately after the learning event, it is good practice to ask someone other than the facilitator to administer and collate the information.

- If handed out some time later, it is recommended that a mechanism to promote a high response rate be incorporated (e.g. encourage the learner's supervisor to allow him/her to complete the questionnaire on company time).

\section{[Beginning of boxed feature: Building Your Skills]}

The design of a reactions level questionnaire is not an easy task. It requires that you carefully consider what data you want to collect, the content and wording of the questions, the use of appropriate types of questions, and the format and layout of the survey. As the HRD Manager of our fictitious international car components company, devise a questionnaire to establish the views of the warehouse fork-lift drivers after they have completed a course on the correct loading/unloading procedures. Consider what questions you would pose about the structure and content of the programme, in addition to inquiring about the delivery methods and techniques utilised by the facilitator. Figure 10.2 may assist your deliberations, as it outlines a generic format for a post-programme reactions level questionnaire.

[End of boxed feature]

[Beginning of boxed feature]

Figure 10.2 Example of a Reactions Level Post-Programme Questionnaire 
We would be grateful if you would complete this questionnaire to help us improve the learning event that you have just attended. Your honest and constructive comments will enable us to build an improved programme for future participants.

Please indicate how you would rate the following elements of the programme:

\begin{tabular}{|l|l|l|l|l|l|}
\cline { 2 - 6 } \multicolumn{1}{l|}{} & Excellent & Good & Average & Poor & Comments \\
\hline Topic 1 & & & & & \\
\hline Topic 2 & & & & & \\
\hline Topic 3 & & & & & \\
\hline $\begin{array}{l}\text { Usefulness of overall } \\
\text { content }\end{array}$ & & & & & \\
\hline $\begin{array}{l}\text { Structure of } \\
\text { programme }\end{array}$ & & & & & \\
\hline Length of programme & & & & & \\
\hline $\begin{array}{l}\text { Standard of slides and } \\
\text { handouts }\end{array}$ & & & & & \\
\hline $\begin{array}{l}\text { Timing of programme } \\
\text { Suitability of venue }\end{array}$ & & & & & \\
\hline
\end{tabular}

Please indicate how you would rate the programme facilitator:

\begin{tabular}{|l|l|l|l|l|l|}
\cline { 2 - 6 } \multicolumn{1}{c|}{} & Excellent & Good & Average & Poor & Comments \\
\hline Knowledge of subject & & & & & \\
& & & & & \\
\hline
\end{tabular}




\begin{tabular}{|l|l|l|l|l|l|}
\hline Presentation skills & & & & & \\
\hline Dealing with questions & & & & & \\
\hline $\begin{array}{l}\text { Controlling the } \\
\text { programme }\end{array}$ & & & & & \\
\hline Interpersonal skills & & & & & \\
\hline Enthusiasm & & & & & \\
\hline Support provided & & & & & \\
\hline \\
Did you find the programme of benefit to you?
\end{tabular}

Please elaborate on your response:

Could you please indicate the learning points from the programme that you are most likely to apply in your work:

Please use the space provided to indicate if you have any suggestions that could be incorporated into future programmes (e.g. expanding, omitting and/or adding topics): 
Please use the space provided to include additional comments that you would like to make on any aspect of the programme:

Signed (optional):

Department:

Name of programme:

Facilitator:

Date:

[End of boxed feature] 


\section{[C] Level 2}

At this level measurement tools are employed to determine the degree of learning achieved and to assess the design of the programme to identify whether it accomplished the objectives set (Garavan et al., 2003). This entails utilising methods that gauge the acquisition of before and after knowledge and skills. The learning objectives that were developed in the design phase specify the outcomes that will signify whether the learning has been successful, thus the appropriate measurement instruments were determined during the identification of HRD needs [MAKING LINKS: See Chapter 7]. Evaluation at the learning level should appraise the same things in the same way as in the TNA. The needs analysis is, therefore, the "pretest". A similar analysis at the conclusion of the programme will indicate the "gain" in learning.

The devices available for pre- and post-testing of learning are participant selfassessment (e.g. learning logs), written tests (e.g. examinations), practical tests (e.g. simulations), and questionnaires. Mechanisms applied at this stage should demonstrate that the achievement of the new knowledge and skills is directly linked to the learning experience. Bramley (2003) recommends that a learner's knowledge of facts can be gauged with objective tests (e.g. requesting the participant to select the correct alternative from a number offered). To determine a person's knowledge of procedures open-ended, short-answer questions can be posed and to ascertain their ability to analyse situations it is recommended that open-ended, free expression questions are asked (e.g. identifying his/her decision-making process). Skills are generally evaluated by means of practical tests where either the learner is set a task and the finished product is graded at the end of the programme, or the learner's performance is reviewed throughout the activity so that the methods deployed can be appraised. Such tests could entail establishing the learner's ability to conduct simple procedures (usually with the aid of notes and instructions), perform proficient actions (often requiring considerable practice), or to judge whether a piece of accomplished work is of acceptable quality.

\section{[C] Level 3}

Measurement at this level (behaviour) is concerned with identifying the degree of improvement in the learner's performance and behaviour on-the-job as a result of the 
intervention. This process is called transfer of learning [KEY TERM: occurs when learning in one situation impacts on a related performance in another context], a phenomenon that we explore in greater detail later in the chapter (see Section on "Enabling a Culture of Effective Evaluation"). According to Garavan et al. (2003) the aim of evaluation at this stage (level 3 ) is to:

- Examine the analysed learning needs to ascertain if these were accurate in their assessment of what was required to augment the individual's performance and behaviour.

- Review the effectiveness of a particular learning event and the methods used, taking account of the passage of time, which should assist the participant to make an objective appraisal.

- Explore how successful the jobholder has been in applying what he/she learned to the workplace.

- Determine whether the learning has had an impact on overall organisational goals.

The tools used should provide the learner with an opportunity to reflect on the completed programme and ascertain how he/she intends to utilise the learning in his/her employment situation. This entails gauging the learner's attitude, their feelings, values, beliefs, and opinions that support or inhibit behaviour, and, consequently, influence motivation towards incorporating newly acquired knowledge and skills into normal work routines [MAKING LINKS: See Chapter 4]. Interviews, questionnaires, observation, performance records, performance appraisals, reflective diaries, and attitude surveys can all be relied upon to evaluate this transfer. The relevant method can be administered when the learner returns to the workplace and at agreed periodic timeframes thereafter. The time lag for assessing application of learning depends on the learning objectives. It is suggested that the more complex the objective(s), the longer the interval between the cessation of the intervention and the behaviour level assessment (Blanchard and Thacker, 2013).

\section{[C] Level 4}

At the fourth level of an evaluation hierarchy (results) the focus shifts from postprogramme consequences to the affect of the HRD process on the firm as a whole. 
Examining the impact of a learning programme on corporate effectiveness can be conducted using a variety of performance indices, such as productivity, cost savings, and timeliness. The interconnections between organisational outcomes, job performance and behaviour, and the learner's KSA should be clearly articulated in the TNA [MAKING LINKS: See Chapter 6]. This creates a causal relationship that specifies if certain KSAs are developed, and learners employ them on-the-job, then particular corporate metrics will occur. Tracking performance indices over time allows a company to assess whether the learning produced the desired changes to organisational outcomes. Examples include analysing customer complaint records, customer retention rates, accident statistics, absenteeism percentages, and staff attrition quotients.

\section{[C] Level 5}

The final level is focused on ascertaining a ROI. This tool assists HRD professionals and management to identify if learning programmes are beneficial to the organisation by calculating the financial return on the firm's investment. $\mathrm{ROI}$ is calculated as the ratio of money gained or lost on a venture relative to the amount of money expended. According to Phillips and Gully (2014), the basic definition of a percentage $\mathrm{ROI}$ is:

$$
\mathrm{ROI}(\%)=\frac{\text { Learning Benefits }- \text { Learning Costs }}{\text { Learning Costs }} \times 100
$$

A positive $\mathrm{ROI}$ indicates that the benefits outweigh the costs, thus the intervention should be continued (although further enhancement may also be possible). A negative $\mathrm{ROI}$ means that costs outweigh benefits and suggests that the undertaking should be changed or discontinued unless additional advantages exist that have not been considered (e.g. heightened employee morale). Translating learning initiatives into monetary terms indicates that such events are investments and will generate future gains (Werner and DeSimone, 2012). Engaging in ROI analysis can also improve the image of the HRD department by demonstrating that its activities make a financial contribution to corporate effectiveness. Additionally, it can confirm that the HRD function operates on a value-for-money basis, and its staff possess budgetary management skills and cost containment abilities (Blanchard and Thacker, 2013). 


\section{[Beginning of boxed feature: HRD in the News]}

\section{Bringing Evaluation into Play in the Field of Football}

Sir Alex Ferguson's 26-year reign as manager of Manchester United Football Club came to an end on Sunday 19 May 2013, with a dramatic 5:5 draw against West Bromwich Albion. This thrilling match, culminating in United being crowned the 2012/2013 English Premier League champions, epitomised Fergie's tenure. Glowing accolades were penned about this man's career following his retirement. Legends from the football community past and present, music celebrities, Hollywood actors, and even prime ministers, added their voices to an extensive roll of honour. But how would HRD professionals assess Ferguson's time as the man responsible for ensuring soccer training sessions resulted in on-going on-field success, and, ultimately, soaring shareholder value? Using the hierarchical models of HRD evaluation we can analyse both his and the Manchester United team's accomplishments.

At the reactions level, tributes were offered by a variety of prominent personalities from all walks of life about Sir Alex's spectacular record. According to Richard Scudamore (English Premier League Chief Executive), "No one's made as great a contribution to the Premier League." A contemporary peer, André Villas-Boas (football manager) referred to Fergie as "The finest manager in world football", a sentiment echoed by another managerial colleague, Roy Hodgson, who noted that "No one will be able to match his achievements".

When examining the learning level, attention needs to be paid to the skills development (technical and tactical nous), winning mentality, work ethic, and team spirit that Ferguson instilled in his players through his unique style of coaching. Continuing the tradition of promoting juvenile talent, and providing gifted young players opportunities to prove themselves, Fergie motivated his team. This professionalism is exemplified by Ryan Giggs, who joined United's Academy as a teenage soccer prodigy and worked his way through the ranks. Making his senior debut for the club in March 1991, he was subsequently appointed player-coach by Sir Alex's initial successor, David Moyes, in June 2013. Less than one year later, in April 2014, he was promoted by the club to the position of interim manager upon Moyes' departure. 
Turning to the next stage of the evaluation hierarchy, the behaviour level, this was epitomised by the action that Fergie took when his team were runners-up in the 2011/2012 English Premier League. Losing the title in the last minute of the season on goal difference to their derby rivals, Manchester City, prompted him to buy the league's leading goal-scorer, Robin van Persie (RVP). Commenting on the importance of RVP's goals in the following campaign's triumph, which resulted in Ferguson's final championship success, David Moyes declared that "Probably what won the league were the goal scorers, Robin especially".

The results level is typified by the number of national, European and international trophies adorning the cabinet room at Manchester United Football Club during Fergie's term. He won 13 Premier League titles, five FA Cups, four League Cups, two Champions Leagues, one Cup Winners Cup, one FIFA Club World Cup, one UEFA Super Cup, one Inter-Continental Cup, and ten FA Charity/Community Shields. Being a serial title winner was enabled by the stability, consistency and cohesiveness of Ferguson's reign, engendering a high-performance culture of success at the club. The adverse impact of a climate of instability was obvious in the season following Ferguson's departure, when his immediate replacement, David Moyes, presided over a turbulent, unpredictable and divisive campaign in 2013/2014.

When considering the final level, ROI, Manchester United is one of the wealthiest and most widely supported soccer clubs in the world. After being floated on the London Stock Exchange in 1991, the club was purchased by Malcolm Glazer (Chief Executive of First Allied Corporation) in May 2005 in a deal pricing the company at almost $£ 800$ million. In August 2012 Manchester United made an initial public offering on the New York Stock Exchange. Eight months later, in January 2013, United became the first sports team in the world to be worth $\$ 3$ billion. Forbes Magazine valued the club at $\$ 3.3$ billion $-\$ 1.2$ billion higher than the next most valuable sports team (the Dallas Cowboys American football team).

Q. Apply the Phillips five-level ROI hierarchical evaluation model to any pursuit that you are interested in (reactions, learning, behaviour, results, return on investment).

Q. Describe each level of this framework as it relates to your chosen activity. 
Q. Illustrate the measurement tools that you could use for each of the five levels in this framework.

Sources:

http://www.bbc.co.uk/sport/0/football/22505640

http://www.bbc.co.uk/sport/0/football/23177876

http://www.bbc.com/sport/0/football/27114788

http://en.wikipedia.org/wiki/Manchester United F.C.

Northcroft, J. (2013) "I've Given Them the Hairdryer", Sunday Times Sport Supplement, 14 July: 11.

[End of boxed feature]

\section{[B] Measures for contextual models}

The difficulty with measuring at levels four and five on a hierarchical model has been recognised by numerous authors (for example, Armstrong, 2014; Martin et al., 2010). This is because individual, team, departmental and/or firm performance occurs within a wide-ranging environment of which learning forms only one part. For example, a low rate of staff turnover may be indicative of high levels of unemployment, a factor external to the circumstances of the company, rather than connected to any internal activities, such as learning programmes. Consequently, many organisations, particularly SMEs, confine their measurement activities to the lower levels of the hierarchical models of evaluation. The CIPD (2013) Learning and Talent Development Survey found that of their 880 respondents more than half use the Kirkpatrick model, or limited stages of it, at least some of the time, although less than a fifth employ the full model always or frequently. The incidence of deployment is contingent upon the size of the organisation, with 56 per cent of companies employing fewer than 1,000 employees never drawing upon the full model compared with 34 per cent of those with more than 1,000 employees. A quarter report that they use limited stages of this model frequently or always, mainly at the reaction level (21 per cent of those with fewer than 1,000 employees, in contrast to 34 per cent of those with more than 1,000 employees). A minority of respondents (14 per cent) always or frequently utilise a contextual system to collate HRD metrics, with over half (55 per cent) of firms employing less than 1,000 staff never availing of such a framework. 
There has, therefore, been a move towards the use of overall measurement tools that are aligned to contextual models of evaluation, which explore mechanisms to improve corporate performance. Questionnaires, interviews, and observational techniques are also pertinent to contextual models. Unlike the hierarchical tradition, however, contextual frameworks adopt an integrated perspective to learning. For example, Warr et al.'s (1970) CIRO model scrutinises the manner in which needs are identified, learning objectives are devised, and the way that objectives link to, and support, pre-planned competences and competencies. Additionally, it considers how these components reflect the culture and structure of the company. This type of evaluation confirms (or refutes) the need for capacity-building, that is, whether those involved in a learning initiative require further strengthening of their skills, competencies and abilities. For example, Fuchs, a global organisation based in Germany producing and distributing lubricants, takes account of HRD metrics when evaluating its social sustainability [MAKING LINKS: See Chapter 14]. The company sets human resource related measurement tools, called key performance indicators (KPIs), and reports on their achievement in its annual accounts. It has increased the average number of further education hours per employee continuously since 2010 . In that year each staff member attended an average of 9 hours of further education, but by 2013, this had risen to 17 hours (Fuchs, 2013).

The CIPD Partnership Model of Learning (Anderson, 2007) mentioned previously incorporates the perspective of all stakeholders in the development of metrics that typify the distinctive characteristics of the company. This measurement approach advocates:

- Taking stock of the extent to which learning activities are aligned with the firm's strategic priorities.

- Reviewing the evaluation and reporting mechanisms that are currently used.

- Ascertaining the most appropriate and timely methods to assess the significance of learning for the organisation under four categories of measurement - learning function, ROI, ROE, and benchmark and capacity indicators. 
The Partnership Model considers the use of scorecard techniques to quantify the value of learning. An example of such a benchmark tool is the stakeholder scorecard (Nickols, 2005), a methodology that contends that the sustained success of a firm is a function of the extent to which the needs of its different stakeholders are balanced, without sacrificing any one to the other. With regard to a HRD intervention, Nickols (2005) maintains that there are four key stakeholders (senior management, learners, facilitators, and the learner's supervisor). The steps involved in preparing a stakeholder scorecard are to:

- Identify the stakeholder groups.

- Determine the contributions received from, and the inducements provided to, each stakeholder group.

- Prioritise the contributions from the perspective of the organisation, and prioritise the inducements from the standpoint of the stakeholders.

- Establish measures of the contributions and inducements.

- Apply the measures.

Employing this approach to a HRD evaluation indicates that stakeholders attach different values to the various aspects of learning evaluation, therefore a $\mathrm{ROI}$ approach, which is the key focus of the hierarchical models, may not satisfy all constituents equally. Consequently, it is argued that a contextual perspective to measurement is more relevant (Anderson, 2007). We will now examine how to take into account the needs of the key participants in the learning process when conducting a HRD evaluation.

\section{[A] Enabling a Culture of Effective Evaluation (How)}

Learning evaluation provides information that is critical to the successful operation of an organisation. It is, however, often conceived of as a weak link in the systematic HRD cycle. According to Gibb (2002: 107) "it is the step most likely to be neglected or underdone". Lack of an assessment procedure or an inappropriate approach to appraisal, can result in learning that is wasteful of financial and human resources, and, furthermore, generate inadequate data for executive decision-making. To enable learning interventions to enhance organisational functioning, it is recommended that companies create a culture of effective evaluation by: 
- Appreciating that organisational blockages exist and the major stakeholders in the HRD process may inadvertently augment these barriers and inhibit the application of learning to the workplace.

- Developing a climate of collaboration so that the principal stakeholders work in partnership and adopt a coherent approach to surmount any potential difficulties regarding learning transfer.

\section{[B] Appreciate the existence of organisational blockages}

Organisations should recognise that conducting an evaluation can be a challenging exercise. Numerous reasons for not adequately assessing learning interventions have been identified. It has been argued that many of the shortcomings associated with measurement difficulties can be traced to the chief HRD stakeholders. As previously noted, evaluation can be conceived from three different stakeholder perspectives. Table 10.3 provides a summary of the possible barriers that impinge on creating an appropriate corporate culture for effective evaluation. It explores these potential organisational blockages from the standpoint of the central constituents in the HRD domain [MAKING LINKS: See Chapter 5]. 
Table 10.3 Summary of Potential Organisational Blockages to Evaluation from Perspective of Key Stakeholders

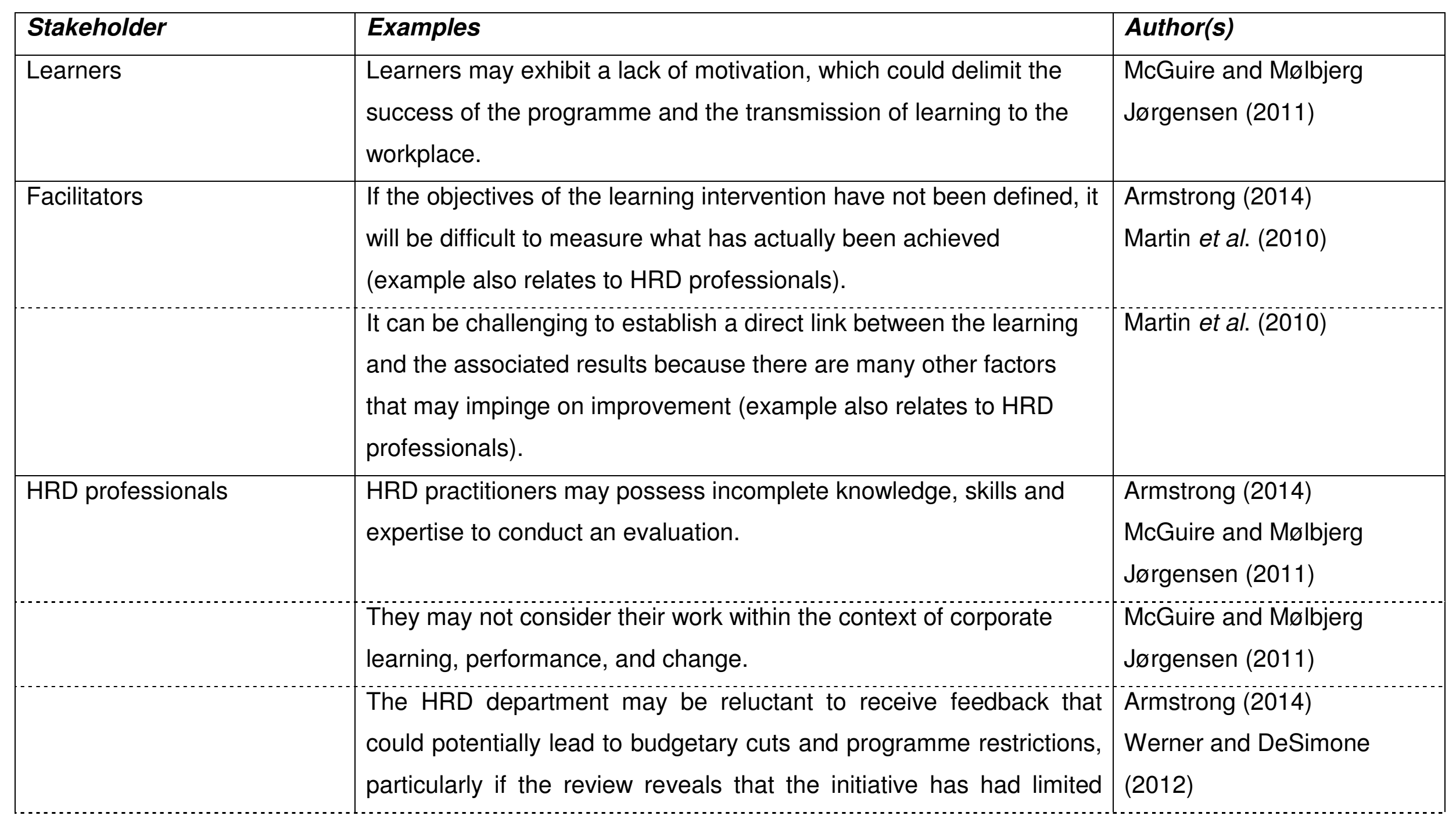




\begin{tabular}{|c|c|c|}
\hline & impact (example also relates to facilitators). & \\
\hline & $\begin{array}{l}\text { Constrained HRD funding may mean that resources are devoted to } \\
\text { learning provision rather than evaluation (example also relates to } \\
\text { organisational decision-makers). }\end{array}$ & Armstrong (2014) \\
\hline Supervisor and colleagues & $\begin{array}{l}\text { An absence of appropriate support mechanisms for the learner may } \\
\text { occur, such as a dearth of practice opportunities, and a lack of } \\
\text { constructive feedback. }\end{array}$ & $\begin{array}{l}\text { Garavan et al. (2003) } \\
\text { McGuire and Mølbjerg } \\
\text { Jørgensen (2011) }\end{array}$ \\
\hline \multirow[t]{2}{*}{$\begin{array}{l}\text { Organisational decision- } \\
\text { makers }\end{array}$} & $\begin{array}{l}\text { Senior management may not request information on the effect of the } \\
\text { learning that was delivered. }\end{array}$ & Armstrong (2014) \\
\hline & $\begin{array}{l}\text { Costs may outweigh benefits, particularly as considerable resources } \\
\text { are expended to assess learning thoroughly, so any outlay has to be } \\
\text { balanced against what is learned from the analysis. }\end{array}$ & Martin et al. (2010) \\
\hline
\end{tabular}

Based on ideas presented by Armstrong (2014), Martin et al. (2010), Garavan et al. (2003), McGuire and Mølbjerg Jørgensen (2011), and Werner and DeSimone (2012). 
When examining the consequences of not conducting a systematic appraisal of the HRD process from each of these points of view, Garavan et al. (2003) note that the:

- Learner reaction, plus their development and progress is not recorded.

- Facilitator performance is not measured.

- Learning event efficiency and effectiveness is not assessed.

- Changes in KSA levels are not linked to the learning intervention.

- Transfer of learning to the work environment is not quantified.

- Organisation is unable to carry out a cost-benefit analysis.

Considering evaluation from the standpoint of the key personnel involved in the HRD process (learners, facilitators, HRD professionals, supervisors and colleagues, and decision-makers) helps us to understand where potential blockages may occur and how they may be surmounted. This assists the firm to formulate and implement learning initiatives that support individual, team, departmental and organisational effectiveness, including learning transfer [MAKING LINKS: See Chapters 2, 3, 4 and $5]$.

\section{[B] Develop transfer of learning among key stakeholders}

The importance of building a partnership approach between the main stakeholders in the HRD process has been recognised by many commentators (for example, Anderson, 2007; Harrison, 2009; McGuire and Mølbjerg Jørgensen, 2011). This involves assessing what the company's business priorities are and how the principal constituents involved in learning can contribute to meeting these objectives (topdown approach to strategic HRD) [MAKING LINKS: See Chapter 2]. It also necessitates facilitating learners to manage the move from being in an education environment obtaining new knowledge and skills, to performing the job on an enhanced basis in the workplace (bottom-up approach to strategic HRD) [MAKING LINKS: See Chapter 2].

This transition is called learning transfer and it entails the application of the KSA gained from the learning event to the job, and subsequent maintenance of them over a defined period of time. Garavan et al. (2003) distinguish between two types of learning transfer. Specific or pure transfer happens when newly acquired skills 
practiced during the learning event are carried out in precisely the same manner in the work setting, such as operating proprietary software packages customised to the company's requirements; while generalisable transfer occurs when the participant learns in a classroom situation to execute tasks in ways that are similar, but not identical to, the sequence in which they are performed in the workplace, such as using off-the-shelf software packages. Brinkerhoff (1987) maintains that learning events alone typically result in only 15 to 20 per cent of learning being applied to onthe-job performance and behaviour. According to Baldwin and Ford (1988) the factors affecting the successful application of learning to the workplace can be divided into three categories: learner characteristics (personality, ability, and motivation effects); programme issues (pedagogical principles of design, content, structure, sequencing, and delivery); and work environment features (organisational supports, continuous learning culture, and task constraints). Figure 10.3 graphically depicts the alignment of these activities carried out by the actors in the HRD sphere with the firm's strategic objectives.

Figure 10.3 Aligning Strategic Objectives and HRD Activities Among Collaborative Constituents

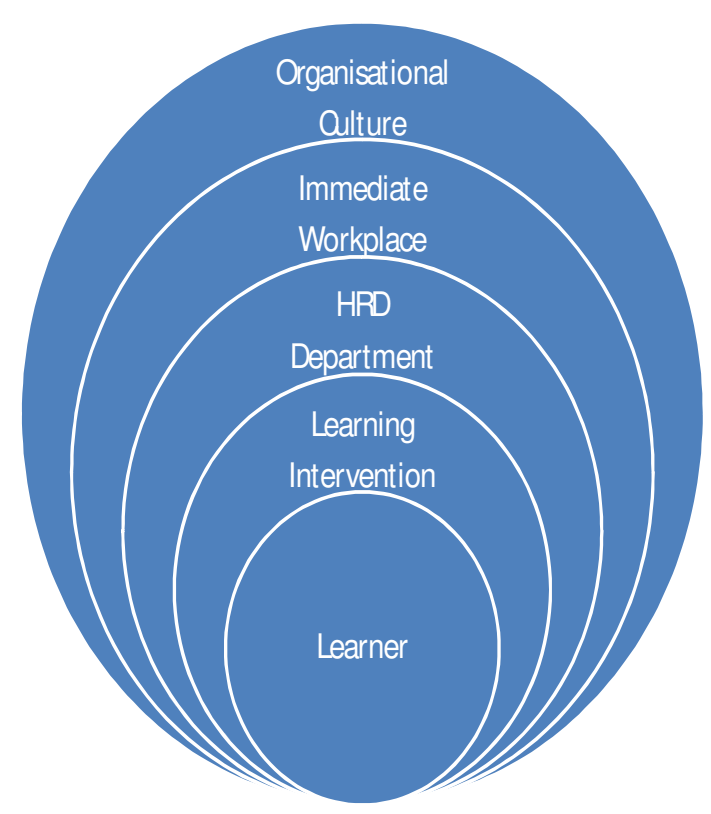


For evaluation to make a significant contribution to improving the quality of learning and positively impact on firm performance, it should be supported by an appropriate corporate culture (Harrison, 2009). An important foundation stone is usually an organisational learning strategy, which articulates core values and policies [MAKING LINKS: See Chapter 2]. At the heart of such an ethos the key partners take joint ownership for learning, work in collaboration to identify learning needs, ensure that the most suitable learning solution is provided, and promote the application of relevant KSA to the workplace. This entails developing strategies to facilitate learning transfer, including the following (Garavan et al., 2003; McGuire and Mølbjerg Jørgensen, 2011):

- Involvement of the learner, supervisor and colleagues, HRD department, and facilitator in the four stages of the HRD cycle.

- Provision of information detailing the benefits of the learning and the rationale for attending the programme prior to commencement of the intervention.

- Utilisation of appropriate evaluation models and measurement tools before, during and after the learning initiative.

- Similarity between the learning and performance contexts to assist effective application, as a positive correlation has been found between these two areas.

- Opportunities for learners to practice their skills in a safe, constructive environment, both during the event and on return to the workplace.

- Emphasis on colleagues attending learning events on a group basis, rather than as individuals, as peers can provide post-programme assistance, and even be considered potential coaches.

- Focus on devising realistic action plans on completion of a learning activity, which can then be monitored and reviewed on an on-going, periodic basis in the work environment.

- Encouragement offered, particularly from supervisors, to learners on return to the work setting.

- Use of relapse prevention strategies that reinforce learning outcomes and minimise skill erosion, such as learner log books, reflective journals, support groups, and refresher sessions. 
- Access to appropriate resources (equipment, facilities, money, time) before, during and after the learning endeavour.

When a firm is designing, implementing and reviewing its HRD evaluation process with a view to facilitating transfer of learning it needs to recognise the factors that are relevant to its specific set of circumstances. This entails developing a strategic perspective to reinforce learning transfer by integrating the evaluation of learning programmes with the company's HRD strategy, which, in turn, is linked to the overall business strategy.

\section{[Beginning of boxed feature: Building Your Skills]}

For most organisations, assisting the transfer of learning does not mean introducing new processes, but usually requires combining current HRD policies, procedures and practices. As the HRD Manager of our fictitious international car components company, consider the issue of learning transfer in relation to the warehouse fork-lift drivers participating on a loading/unloading procedures course. What actions should you take before, during and after the training to ensure positive application from the programme to the workplace? Who do you need to liaise with? What difficulties would you expect to encounter? How do you anticipate you will overcome these challenges?

\section{[End of boxed feature]}

\section{[Beginning of boxed feature: Active Case Study]}

\section{Applying HRD Principles to the Cosmetics Industry: Case Study from Oriflame's Research and Development Subsidiary}

The Oriflame Group is an international beauty company selling direct in more than 60 countries worldwide. Its portfolio of nature-inspired innovative beauty products (skincare, fragrances, toiletries, wellness products, cosmetics) are marketed through a global sales force of 3.4 million independent consultants, who together create annual sales of $€ 1.5$ billion. Respect for people and nature underpins the company's philosophy, mission statement and operating principles, which, in turn, is reflected in its social and environmental policies. For example, Oriflame supports numerous national and international charities and is a co-founder of the World Childhood Foundation. 
Having its origin in Sweden, Oriflame provides a global human resource management (HRM) service to its 7,500 employees, offering expertise in the areas of talent recruitment, people development, and rewards. It also operates a HR Shared Service, with the subsidiaries in each country supported by centralised expertise in learning and development (L\&D), compensation and benefits, and administration, delivered through in-country business partners.

All research and development $(R \& D)$ relating to Oriflame's products emanates from its Irish operation. This unit employs 165 professional staff in chemistry, biology and general business, with over one tenth educated to doctoral level (12 per cent), one fifth to Masters level (22 per cent) and more than half (53 per cent) to degree standard. To compliment and supplement the company's product innovation, the R\&D subsidiary devises, develops and implements pioneering HRM projects. These are initially formulated for Ireland, with successful programmes being adapted for global use in the Oriflame group. The foundation stone of these initiatives is the Capability Framework, which advises the company what capabilities staff should have (or aspire to have) to enable them to do an effective job. By defining these capabilities, Oriflame ensures that it recruits the right people, clarifies to employees what is expected of them, identifies any skills gaps and learning needs, generates individual learner plans, and assists internal career management and success planning.

Integral to Oriflame's Capability Framework is a commitment to continuous learning and improvement. This concept is embodied in the company's L\&D Programme, which facilitates learning in its broadest sense, reinforces effectiveness and motivation through appropriate actions, and systematically develops knowledge, skills, technical competence and behavioural competencies of staff. It aims to promote an organisational culture that fosters leadership and staff profiles that are dynamic and aligned with the organisation's values (togetherness, spirit, passion) and evolving needs. This is achieved by embedding L\&D in five underlying principles:

1. Regarding learning as a strategic activity.

2. Integrating learning with the short- and long-term needs of the organisation. 
3. Aiming to develop the "whole" employee.

4. Providing equitable access to all employees.

5. Evaluating learning effectiveness by its ability to satisfy organisational requirements.

The areas of L\&D considered a corporate priority are those that are:

- Mandatory to perform a function or a role within the organisation, such as:-

- Safety-training and/or safety-awareness.

- Technical skills improvement programmes, including language training.

- Programmes to improve leadership skills, supervisory skills and the required managerial capabilities.

- Necessary to ensure successful integration into Oriflame and/or the local area, such as:-

- Induction so that all employees have a common understanding of the corporate mission.

- Software training to enable personnel at all levels to effectively utilise the company's systems.

- Basic language and safety training.

- Aimed at fostering mutual understanding within the organisation, such as:-

- Core communication programmes.

- Actions to raise awareness of workplace diversity issues.

Decisions relating to budget allocation are determined by balancing the subsidiary's business priorities, the individual needs of its employees, and the appropriateness and cost effectiveness of the learning. Learning interventions are the responsibility of both the functional departments and the HR department, with ultimate accountability contingent upon strategic and operational imperatives. Such interventions are provided through participation in internal formal programmes, external training programmes and/or other appropriate formal or informal actions. Learning is evaluated according to the four levels of Kirkpatrick's model and the feedback generated improves the four stages of the systematic HRD cycle (needs analysis, design, delivery, evaluation). 


\section{Questions}

As the HR Director of Oriflame's R\&D Operation in Ireland, consider your responses to the following questions that the Global HR Manager from Corporate Head Office has posed regarding the roll-out of the new L\&D Programme to all of the company's worldwide subsidiaries by:

1. Providing examples of the learning interventions that could be included in the:-

a. Internal formal training programmes.

b. External training programmes.

c. Other appropriate formal or informal training actions.

2. Explaining how the learning interventions could be assessed using Kirkpatrick's four-level model of evaluation.

3. Considering how the L\&D budget could be structured and allocated to satisfy Corporate Head Office and local subsidiary needs.

\section{[End of boxed feature]}

\section{[A] Summary}

This chapter highlights the importance of evaluating HRD programmes, because evaluation can directly contribute to improving corporate effectiveness [MAKING LINKS: See Chapter 2]. HRD professionals need to provide evidence to the organisation of the benefits of their learning, training, and development activities, thus the HRD function has to consistently assess and measure its learning and development programmes [MAKING LINKS: See Chapters 7, 8 and 9]. The evaluation phase of the systematic HRD cycle should, therefore, prove worth and impact; control for quality and efficiency; and lead to improvements for future initiatives. To achieve these aims, HRD staff must understand the distinction between the two different philosophical perspectives to evaluation (hierarchical and contextual models) and apply appropriate measurement tools (such as reactions level post-evaluation questionnaires, interviews, examinations, before and after tests, and calculations to gauge monetary return). It is also important that the organisation creates a culture of effective evaluation by assisting the HRD stakeholders to collaborate and work in partnership to successfully transfer learning from the classroom situation to the workplace [MAKING LINKS: See Chapter 5]. 


\section{[A] Chapter Review Questions}

1. Explain the purpose of evaluating HRD programmes, making specific reference to the benefits accruing to an organisation from engaging in such an activity.

2. Compare and contrast hierarchical models of evaluation with contextual models of evaluation.

3. Describe the stages in Kirkpatrick's four-level model of evaluation.

4. Distinguish between the two key outputs from the evaluation process, that is, process data and outcome data, clearly outlining the stage in the HRD cycle when each output occurs.

5. Discuss any three evaluation measurement tools available to a company and provide an example of the learning intervention that each tool could evaluate.

6. Identify the basic definition of a percentage $\mathrm{ROI}$ formula and include examples of the potential benefits and costs that could be contained in this ratio.

7. Compare and contrast specific (pure) transfer of learning with generalisable transfer of learning.

8. List seven strategies that an organisation could utilise to assist learning transfer.

\section{[A] Further Reading}

Blanchard, P.N. and Thacker, J.W. (2013) Effective Training: Systems, Strategies, and Practices, Pearson Education Limited, Harlow.

Bramley, P. (2003) Evaluating Training, $2^{\text {nd }}$ edition, CIPD, London.

Brinkerhoff, R.O. (1987) Achieving Results Through Training: How to Evaluate HRD to Strengthen Programs and Increase Impact, Jossey-Boss, San Francisco, California.

Hutchins, H.M., Burke, L.A. and Berthelsen, A.M. (2010) A missing link in the transfer problem? Examining how trainers learn about training transfer, Human Resource Management, 49(4): 599-618.

Kirkpatrick, D.L. and Kirkpatrick, J.D. (2006) Evaluating Training Programs, $3^{\text {rd }}$ edition, Berrett-Koehler Publishers, San Francisco, California.

Laker, D.R. and Powell, J.L. (2011) The differences between hard and soft skills and their relative impact on training transfer, Human Resource Development Quarterly, 22(1): 111-22. 
Phillips, J.J. (2011) Handbook of Training Evaluation and Measurement Methods, $3^{\text {rd }}$ edition, Routledge, Oxon.

Saks, A.M. and Burke, L.A. (2012) An investigation into the relationship between training evaluation and the transfer of training, International Journal of Training and Development, 16(2): 118-27.

Tomé, E. (2009) The evaluation of HRD: A critical study with applications, Journal of European Industrial Training, 33(6): 513-38.

Werner, J.M. and DeSimone, R.L. (2012) Human Resource Development, $6^{\text {th }}$ edition, Cengage Learning, Mason Ohio.

\section{[A] Useful Websites}

http://www.cipd.co.uk/NR/rdonlyres/94842E50-F775-4154-975F-

8D4BE72846C7/0/valoflearnnwmodvalca.pdf - Anderson's article explores how HRD practitioners can measure and demonstrate the value of learning for their organisation.

http://www.ilo.org/Search3/search.do?searchWhat=evaluation+of+HRD+programme s\&searchLanguage $=e n-A$ repository of HRD resources, including evaluation programmes, can be accessed from the website of the International Labour Organization, an agency that promotes rights at work, enhances social protection, and strengthens dialogue on work-related issues.

http://www.kirkpatrickpartners.com/ - The official site of the Kirkpatrick four-level evaluation model incorporating tools and techniques that equip people to create significant value for their stakeholders and demonstrate impact to the bottom line.

http://www.roiinstitute.net/ - A research, benchmarking and consulting organisation providing workshops, publications and consulting services promoting the use of the Phillips' ROI evaluation methodology. 